\title{
Un camino culebrero: La modernidad cultural colombiana en el contexto latinoamericano
}

\section{Artículo de investigación}

Carlos Granés

Ensayista

carlos.granes@cervantesvirtual.com

Recibido: 8 de septiembre de 2019

Aprobado: 30 de septiembre de 2019

Cómo citar este artículo: Granés, Carlos (2020). Un camino culebrero: La modernidad cultural colombiana en el contexto latinoamericano. Calle 14: revista de investigación en el campo del arte 15(28). pp. 222-237. https://doi.org/10.14483/21450706.16251

\section{(c) (1)}

https://creativecommons.org/licenses/by/4.0/deed.es 

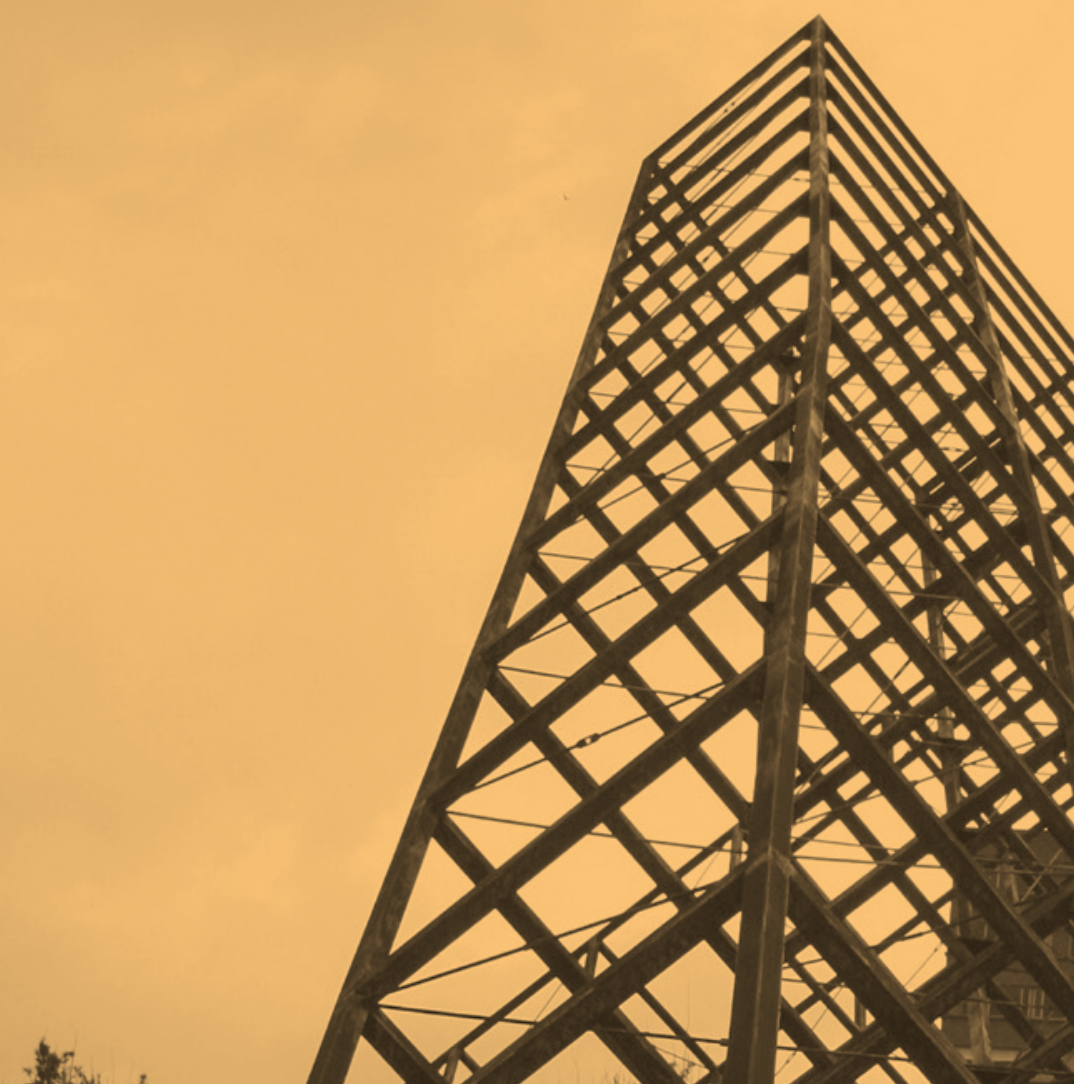

i)

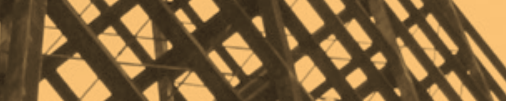

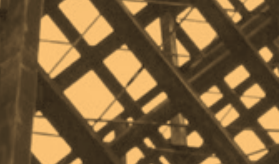

411

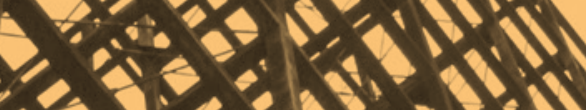

20

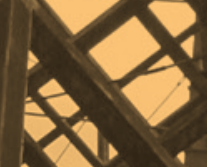

(1)

*

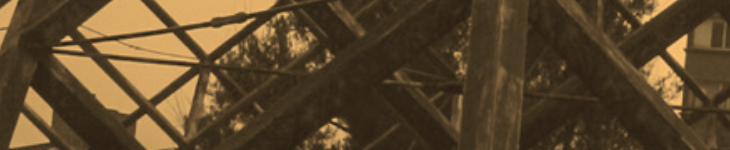

$\therefore$ a
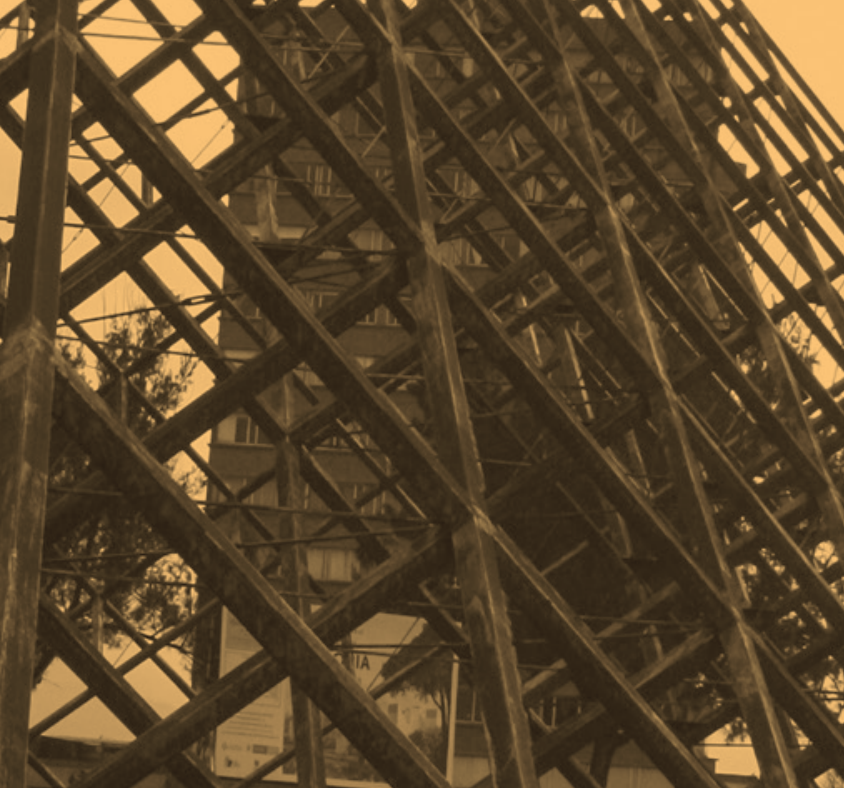

$3\left(\frac{1-4-2)}{21 D}\right.$

It)

3

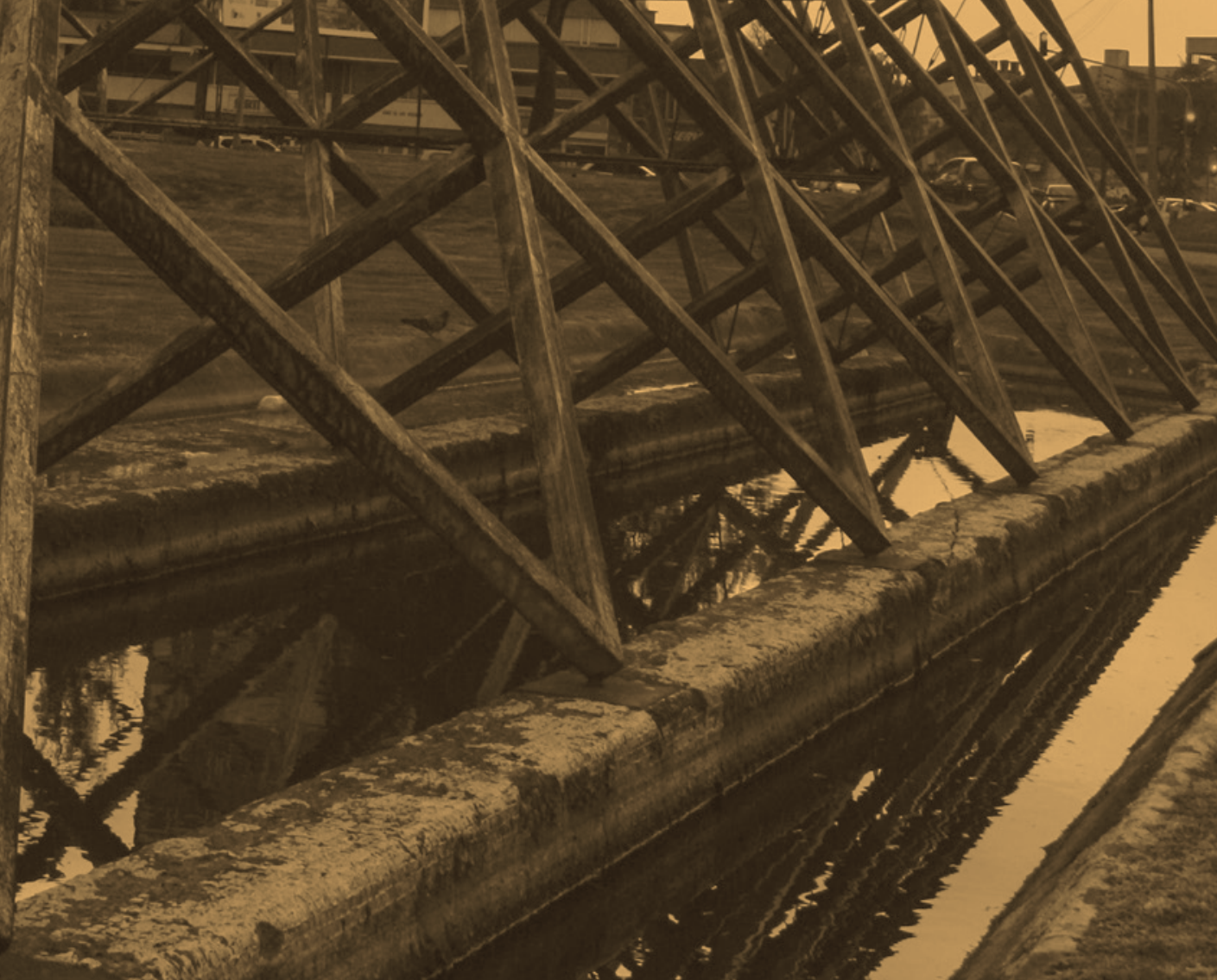




\title{
Resumen
}

Aunque con características propias determinadas por el aislamiento y el poco contacto de los artistas y escritores nacionales con sus colegas de los países vecinos, la modernización cultural de Colombia corrió paralela a la del resto de América Latina. En este ensayo se abordan algunos momentos fundamentales de este proceso -la influencia de las vanguardias, los radicalismos políticos, las tensiones nacionalistas y cosmopolitas- para entender las disputas ideológicas que influenciaron los procesos creativos entre los años veinte y sesenta del siglo pasado. Comparando lo ocurrido en Colombia con lo que estaba pasando en el resto del continente, se aprecian mejor las particularidades de nuestra evolución cultural.

\section{Palabras clave}

Vanguardia; nacionalismo; cosmopolitismo; fascismo; comunismo.

\section{A Twisted Path: Colombian Cultural Modernity in the Latin American Context}

\begin{abstract}
Although its own characteristics were determined by the isolation and little contact of national artists and writers with their colleagues in neighboring countries, the cultural modernization of Colombia ran parallel to that of the rest of Latin America. This essay deals with some fundamental moments in this process - the influence of the avant-gardes, political radicalisms, nationalist and cosmopolitan tensions - to understand the ideological disputes that influenced creative processes between the 1920s and 1960s. Comparing what happened in Colombia with what was happening in the rest of the continent will allow to better appreciate the peculiarities of our cultural evolution.
\end{abstract}

\section{Keywords}

Avant-garde; nationalism; cosmopolitism; fascism; communism.

Un chemin tordu : la modernité culturelle colombienne dans le contexte latino-américain

\section{Résumé}

Bien que ses caractéristiques propres soient déterminées par l'isolement et le faible contact des artistes et des écrivains nationaux avec leurs collègues des pays voisins, la modernisation culturelle de la Colombie a été parallèle à celle du reste de I>Amérique latine. Cet essai aborde certains moments fondamentaux de ce processus - l'influence des avant-gardes, les radicalismes politiques, les tensions nationalistes et cosmopolites - pour comprendre les disputes idéologiques qui ont influencé les processus de création entre les années 1920 et 1960. Comparer ce qui s'est passé en Colombie avec ce qui se passait dans le reste du continent permettra de mieux apprécier les particularités de notre évolution culturelle.

\section{Mots clés}

Avant-garde ; nationalisme ; cosmopolitisme ; fascisme ; communisme.

\section{Um caminho tortuoso: A modernidade cultural colombiana no contexto latino-americano.}

Embora com características próprias determinadas pelo isolamento e o pouco contato dos artistas e escritores nacionais com seus colegas dos países vizinhos, a modernização cultural da Colômbia correu em paralelo com o resto da América Latina. Neste ensaio se abordam alguns momentos fundamentais neste processo- a influência das vanguardas, os radicalismos políticos, as tensões nacionalistas e cosmopolitas - para entender as disputas ideológicas 
que influenciaram os processos criativos entre os anos vinte e setenta do século passado. Comparando o ocorrido na Colômbia com o que estava acontecendo no resto do continente se poder apreciar melhor as particularidades da nossa evolução cultural.

\section{Palavras chave}

Vanguarda; nacionalismo; cosmopolitismo; fascismo; comunismo.

\section{Mailla Jiru Ñambi Katichingapa Nukanchipa Kausaita Kawachingapa}

\section{Maillallachiska}

Nikumi kaipi llakispa kunaura manima lisinsiankuna llugsingapa kawanakuspa Rimangapa kai kilkadur runakuna Munanaku kawachinga kausai ñugpamanda imasami kaska kunaura kami llapa subrigcha manema ñugpacina chimanda paikura ruanaku mana chingachingapa Nukanchipa kausai,mikui,katangakuna atun llagtamanda.

\section{Rimangapa Ministidukuna}

Vanguardia; nacionalismo; cosmopolitismo; fascismo; comunismo. 
metáforas que era capaz de inventar y se convertía en un pequeño Dios que creaba formas, paisajes y geomeEn Colombia no todo empezó en 1922, pero casi. Aquel año había sido trascendental para la modernidad cultural de países como México, Brasil, Perú y Argentina, que vieron surgir el movimiento muralista, el estridentismo mexicano, la Semana de Arte Moderno de Sao Paulo, la publicación del sorprendente Trilce, la obra maestra de César Vallejo, y la revista Proa, dirigida por un jovencísimo Jorge Luis Borges y su mentor, Macedonio Fernández. Empezaba la gran fiesta de la vanguardia, una renovación de la poesía que se llevaría por delante el modernismo de Rubén Darío, de nuestros José Asunción Silva y Guillermo Valencia, y también el de Julián del Casal, Herrera y Reissig y tantos otros, lanzada por jóvenes latinoamericanos que habían viajado a Europa y habían vuelto impregnados de la fascinación por lo salvaje y lo primitivo, la misteriosa enzima que había nutrido la pintura europea desde Gauguin hasta Picasso. Alineando sus plumas y pinceles con Europa, la cultura latinoamericana cambiaba, y con ella cambiaban las actitudes vitales del artista. El decadentismo y la bohemia daban paso al compromiso político, a la pintura social y a una búsqueda de las identidades nacionales. Fértil en el terreno estético, no tanto en el político, este cambio impuso un debate que aún no se resuelve: ¿cuál debe de ser nuestra relación con la Colonia, con las influencias culturales foráneas, con el Imperio, con nuestro pasado? ¿Qué somos? ¿Por qué? ¿Cómo remediarlo? En fin...

Decía, sí, que la cultura colombiana había llegado un tris tarde a esa fiesta, en 1925, con la irrupción de una nueva generación que se puso un nombre muy de la época: Los Nuevos. Y sí, esta nueva camada de jóvenes se sumó al alboroto y al desafío de los viejos valores; se envalentonaron frente a sus mayores y se creyeron una fuente de regeneración, pero, para ser sinceros, les faltó mucho para ser el alma de la fiesta latinoamericana. Digamos, más bien, que se quedaron en un rincón, muy a la bogotana, mirado mal y hablando entre ellos, mientras sus contemporáneos peruanos, mexicanos, chilenos, brasileños o caribeños se tomaban un coctel raro y se pegaban una tremenda fiesta. Los colombianos fueron más parcos en sus rupturas, más atildados en sus experimentaciones, menos entusiastas ante el espectáculo de modernización de las ciudades. Mientras en buena parte del continente se experimentaba con el creacionismo de Vicente Huidobro o con el ultraísmo de Borges, mientras en otros lugares el poeta se emancipaba de la realidad, construía mundos nuevos surgidos de su imaginación, apuntalados con las

de la realidad exterior, en Colombia seguíamos aferrados a nostalgias, idealizaciones grecolatinas, jolgorios bohemios.

El futurismo llegó con enorme fuerza a renovar la poesía en todos lados menos en Colombia. Allá y más allá se escribieron buenos y malos poemas que daban cuenta de los cambios que sufrían las ciudades con las nuevas tecnologías y la modernización de las costumbres. En 1924 el mexicano Maples Arce publicaba Urbe, un largo poema, ilustrado por el muralista Jean Charlot, en el que la ciudad se convertía en el gran escenario del nuevo protagonista del siglo XX, las masas revolucionarias. Mario de Andrade le hacía un homenaje y una declaración de amor a São Paulo en Paulicéia desvairada, de 1922. Se cantaba a los motores, al tranvía, a los postes de luz, al deporte. "Jugador de blanca y roja camiseta, / que, de pronto, arrebatado / zigzaguea, jubiloso la gran $Z$ / de un ataque combinado / junto al otro, que al cruzársele en un paso de emoción / cae al suelo y, trémulo iay....! / se levanta otra vez como de una eléctrica impulsión. / Pero suena el breve pito de un offside / y de nuevo va rodando la pelota / o epiléptica, rebota / en los pies que hacen con ella como encajes por el suelo", escribía en 1925 el peruano Juan Parra del Riego (1943, pp.83-84).

Toda esta euforia creativa apenas resonó entre los poetas colombianos. Puede decirse, incluso, que el más sintonizado con esta nueva sensibilidad ni siquiera fue un poeta sino un cronista, el magistral Luis Tejada, que en sus deliciosas piezas periodísticas mezcló el humor, el ingenio y el oficio para comentar e ironizar sobre los cambios vitales y sociales que asaltaban a la Bogotá de los años veinte. Detrás de él vino Luis Vidales, el único poeta colombiano que rompió verdaderamente con el modernismo; el único que en realidad hizo vanguardia, mezclando el juego y el humor para renovar la mirada y echar un vistazo a la ciudad casi como un niño que sale por primera vez a darse una vuelta por la cuadra.

Al lado de estos dos vanguardistas compartieron sitio en las mesas del café Windsor, su lugar de reunión en el centro de Bogotá, muchos otros intelectuales y poetas llegados de todas las esquinas de Colombia. León de Greiff fue un protagonista incuestionable. Venía de alborotar la paz clerical de la muy conservadora Medellín con su revista Panida, donde en 1915 se había estrenado como sedicioso y nocturno cantor 
de baladas satíricas, dardos precisos que dieron en el corazón etílico de la bohemia colombiana. Lunático y sabio, amigo de la juerga noctámbula, de Poe y del éxtasis, de Greiff fue un sátiro que se emborrachó en Bolombolo haciendo la ronda con el dios Pan, y un niño travieso que le enseñó el pipí a la mojigata sociedad bogotana. Musical y malévolo, inocente y autoirónico, jugó con el lenguaje y jugó consigo mismo. Se dio el lujo de enmarañar las palabras y de inventarse infinidad de alter egos, Leo Le Gris, Matías Aldecoa, Sergio Stepansky, Gaspar von der Nacht, Erik Fjordsson..., y así, jugando con el lenguaje y jugando con su identidad, fue dejando una de las obras más originales de la poesía colombiana. Pero no fue del todo vanguardia. Sus referentes siguieron siendo los simbolistas, y su sensibilidad no dejó de alimentar la nocturna despreocupación por los asuntos mundanos y la indiferencia hacia la vida política que se vivía a ras de calle. Su licor fue el anís, no el furor de la ideología revolucionaria.

En cuanto a la plástica que se hacía en Colombia, lo más parecido a la vanguardia fue Ricardo Rendón, un caricaturista de trazo limpio y estilizado, que a pesar de no exhibir ningún alarde futurista, cubista o socializante que lo emparentara con los artistas mexicanos o argentinos del momento, dejó un retrato humorístico e irreverente de aquellos años de hegemonía conservadora, muy en la línea juguetona de Tejada y Vidales. De manera que Bogotá se modernizaba a media marcha, un tanto ensimismada, un tanto ajena a todo lo que estaba pasando en la literatura y el arte del resto del continente, y un tanto indiferente a los ismos europeos. El aislamiento al que estaba condenada Bogotá en su meseta altiplánica, sumada al efecto de muchos años de conservadurismo político y de los muchos gobernantes que, además de conservadores eran intelectuales de gran cultura, enamorados de Grecia y de Roma y ejercitados desde jovenzuelos en los aros de la gramática, no habían moldeado una sensibilidad proclive a la experimentación o al mundanal alarido del anarquista y de la masa revolucionaria. Los Nuevos empezaban a cambiar esto, pero la lápida con la que luchaban llevaba inscritos los nombres de Miguel Antonio Caro y Rufino José Cuervo, y eso no era ninguna tontería.

Si en Colombia se empezaron a oír los nombres de Apollinaire, de Reverdy, de Claudel o de Gide no fue en el Windsor de Bogotá sino en la revista Voces, que el catalán Ramón Vinyes publicó en Barranquilla entre 1917 y 1920. Fue en la Costa donde la poesía colombiana dejó a un lado esa fascinación por el mundo grecolatino que llenaba los discursos y los poemas de mármoles, laureles, frisos, náyades y dioses mitológicos. El cartagenero Luis Carlos López fue el primero en combatir esa rubiola pasadista con palabras mundanas como “indigestión”, “cangrejo", "pollo asado", "masturbación”, "mamey" y "zapatos viejos": música para los oídos hartos de cisnes, centauros y liróforos celestes.

Barranquilla, puerto al fin y al cabo, estaba destinada a ser la ventana al mundo de Colombia. Bogotá siempre había sido una de las capitales más aisladas de toda América Latina. Excepto por algún diplomático —como el poeta mexicano Carlos Pellicer- que llegaba forzado debido a sus compromisos laborales, por Bogotá no se asomaba nadie. Las noticias del mundo exterior parecían morir de extenuación tratando de remontar el Río Magdalena y la Cordillera Central. Ni La Paz, 1.400 metros más arriba en la montaña, estaba tan aislada, y en gran medida gracias a Puno, una ciudad donde la vanguardia indigenista ardió con intensidad fascinante, y que estaba allí nomás cruzando la frontera. Eso no quiere decir que los procesos culturales colombianos hubieran surgido en una campaña neumática, incontaminados por las ideas y fervores que revolucionaban el resto del mundo. En absoluto. Aunque en Colombia la influencia del APRA peruano fue débil y la del arielismo de 1900 solo consiguió instigar un rabioso antiyanquismo y un nacionalismo vernáculo, con el campesino como símbolo, en ciertos sectores del conservatismo - Laureano Gómez, por ejemplo-, la Revolución mexicana y la Reforma Universitaria de Córdoba de 1918, al igual que la Revolución rusa y el ascenso de Mussolini y del fascismo en Europa, no pasaron desapercibidos para esta variopinta generación de los Nuevos.

\section{II}

Si se mira bien, el caso colombiano tiene ciertos parecidos con el brasileño. No tanto en el terreno estético, ya quisiéramos, sino en el político. Devolvámonos a ese año fundacional de 1922 en que la modernidad daba pasos de gigante en Sao Paulo. Oswald de Andrade ya había ido a París y estaba de vuelta; la pintora Tarsila do Amaral, su pareja, no tardaría en regresar para iniciar un viaje por el interior de su país: querían redescubrir el Brasil salvaje que cautivaba a los europeos. A su lado, esa pareja que a comienzos del 2000 fue el símbolo de lo moderno y lo sexy, Brangelina, era en realidad un espantajo rancio. Tarsiwald, la pintora y el poeta, la pareja desenfadada que en su Cadillac veloz retrocedió en el tiempo hasta la época de las tribus y de los tupies, los creadores que mezclaron la forma moderna 
y el contenido primitivo y le dieron a Brasil una ventana para mirarse a sí mismo y para ser mirado por el mundo, encarnó la modernidad brasileña como nadie. No muy lejos de ellos, Mario de Andrade, Luis Aranha y Menotti del Picchia escribían poemas futuristas; Victor Becheret, Vicente do Rego Monteiro, Emiliano di Calvacanti y Anita Malfati innovaban con la forma. El clima intelectual era propicio para un gran evento artístico que reuniera las nuevas propuestas modernizantes, ya maduras, en los distintos campos culturales. La Semana de Arte Moderno fue justo eso, una oportunidad para que los paulistas vieran cuadros y maquetas, oyeran poemas, manifiestos y conciertos de música, y también para que advirtieran cómo se iban perfilando dos sensibilidades distintas, ambas con un mismo tronco -el interés por redescubrir lo nacional-, pero irreconciliables en términos políticos.

Mario de Andrade, Oswald de Andrade y Tarsila do Amaral serían las figuras más visibles de una actitud internacionalista y cosmopolita, dispuesta a asimilar las influencias culturales extranjeras con estómago brasileño. Se autodenominaron Antropofagia, y como buenos caníbales no le hicieron el feo a ningún nutrimento que pudiera hacer engordar la cultura nacional. ¿Colonialismo luso? Hágale, mijo, sin miedo, no somos puros, somos mestizos y esa es nuestra particularidad y nuestra fortaleza. Como los antecesores barrocos, digerimos y abrasileñamos todo, la pureza es para los ángeles o para los locos. La idea antropofágica resultaba aborrecible para otro grupo que también estuvo presente en los eventos de 1922. El estómago brasileño, pensaban, era intolerante: a lo portugués por saturación y a lo europeo y estadounidense por asco. Estos poetas querían redescubrir lo propio y cercar el país con un cordón sanitario que impidiera la contaminación de los valores brasileños y del alma nacional. Al principio se llamaron los verde-amarillos, luego se reunirían bajo el nombre de Escola da Anta, siempre perseguirían el mismo anhelo: regresar a un pasado en el que las esencias de Brasil brotaban incontaminadas e irradiaban quién sabe qué don maravilloso. Fueron rabiosos nacionalistas en busca del primer hombre no contaminado con el pecado de la Colonia.

Lo interesante aquí es que esta escisión estética produciría una escisión política. Como buenos internacionalistas, los antropófagos acabaron vinculados al comunismo, especialmente Oswald de Andrade y su segunda esposa, Pagu, mientras que los verde-amarillos, místicos de la pureza, formaron un partido político de corte fascista -el Integralismo-, se enfundaron en camisas verdes, inventaron un saludo nazi de brazo alzado y grito vernáculo —Anauê!_-, y en 1938 trataron de dar un golpe de Estado para crear un vergel de brasileñidad purgado de toda contaminación extranjera. Lo que había empezado como un asunto poético, acababa en un gran drama político.

En menor escala, algo similar estaba ocurriendo en Colombia. Unida por deseos renovadores y antipasadistas, por su deseo de dejar atrás a la generación previa, la del Centenario, los Nuevos, pasaron por alto sus propias diferencias ideológicas. Como en la Semana de Arte Moderno, en el café Windsor se reunían personalidades tan distintas como el conservador Rafael Maya, los futuros socialistas Rendón y Tejada, el liberal José Umaña Bernal, y un grupo de revolucionarios que alimentaba la llama del fascismo colombiano, los Leopardos. Antes de ser los Nuevos, todos ellos conformaron el grupo de los Arquilókidas, y juntos, desde junio 23 hasta julio 19 de 1922 (Loaiza, 2008), escribieron una serie de artículos en el diario La República conocidos como las Archilokias: ejercicios de irreverencia y ataque con los que ridiculizaron al establishment cultural colombiano.

Los Leopardos eran Silvio Villegas, José Camacho Carreño, Augusto Ramírez Moreno, Joaquín Fidalgo y Eliseo Arango. Se habían formado como grupo en 1921 y tres años después lanzaban su Manifiesto nacionalista, un grito de guerra en el que reivindicaban la estirpe conservadora y nacionalista del campesino. Si el obrero se afiliaba a las causas de la izquierda, el campesinado seguía encarnando "el espíritu de la tierra" (Arias, 2007, p.171). Influenciados por las ideas reaccionarias de Maurice Barrès y de la revista Action Française, desplegaron un nacionalismo desacomplejado en busca de héroes y mitologías con los cuales enfebrecer los sentimientos patrios. La imagen del caudillo todopoderoso los obsesionó, y claro, en Colombia ese titán heroico no podía ser otro que Bolívar, pero no el Bolívar emancipador sino el autocrático de los últimos años, el que quiso acabar con la vida parlamentaria y establecer un sistema vertical, cuasi monárquico. "Sobre la Colombia decrépita, vergonzante, raquítica - decía José Camacho Carreño-; espectro de legalidad...; sin áspera noción de fiereza criolla ni de varonía nacional, con endeble cultura, abismo de ideales abarrancados; renegado de todo principio másculo, de la autoridad, de la Iglesia, de la gloria guerrera, de la arbitrariedad ambiciosa, reconstruyamos la Colombia de Bolívar, almizclada y atormentada como el Padre" (Arias, 2007, p.171). 
"Fiereza criolla", "varonía nacional", "gloria guerrera"..., ahí estaba el embrión del fascismo colombiano. Como en Argentina con Leopoldo Lugones, en Nicaragua con José Coronel Urtecho y los demás miembros del movimiento de vanguardia, en Brasil con Plinio Salgado y el Integralismo, en Paraguay y en Bolivia con la generación de escritores que surgió después de la Guerra del Chaco, el fascismo surgía en Colombia en las tertulias literarias para dar luego el salto a la política.

La primera pelea de los Leopardos la dieron en el seno del Partido conservador. La modernidad que proclamaban debía llevarse por delante la mansedumbre y el conformismo de los viejos patriarcas del partido, domesticados por las rutinas parlamentarias. Villegas y sus seguidores querían acción, demostraciones de fuerza, imposición viril de las ideas y un gobierno fuerte que se dejara de melindres democráticos y restableciera la grandeza nacional con el liderazgo de un caudillo autoritario. Lo curioso es que al mismo tiempo, en las filas contrarias, algunos liberales empezaban a deslindarse de la doctrina individualista y a interesarse por las ideas de izquierda. Luis Tejada y José Mar dirigían El Sol, un diario liberal que coqueteaba con el socialismo, y Gaitán preparaba la tesis con la que se graduaría en 1924 de abogado: Las ideas socialistas en Colombia. Entre los liberales, Tejada era el más decidido a dar el salto a la izquierda radical, formando un partido comunista. Contaba con José Mar, con un ruso exiliado en Bogotá llamado Silvestre Sawinsky, con Luis Vidales y otros cuantos, un pequeño y decidido grupo con el que emprendió la conquista ideológica de las masas obreras. Se reunieron con otros izquierdistas, programaron un primer congreso comunista, escribieron algún manifiesto dirigido a los obreros. Pero el camino al comunismo era largo y en alguna curva se le atravesó a Tejada una enfermedad mortal, la tuberculosis, que acabó con su vida en 1924, cuando apenas tenía veintiséis años. Aunque el impulso hacia el comunismo sufrió un frenazo inapelable, Vidales recogió el testigo y en 1930 estaría presente en la fundación del Partido Comunista. De la misma mesa del café Windsor salían el fascismo y el comunismo colombianos.

\section{III}

La llegada de los años treinta fue catastrófica para América Latina. El crack del 29, que había debilitado las economías y arruinado a muchos países que dependían del banano o del café, supuso un desprecio generalizado por el liberalismo, por el comercio internacional y por la democracia. Todas aquellas ideas que habían regido la vida de los países entre finales del siglo XIX y 1930, de pronto parecían obsoletas, perjudiciales, superadas por los acontecimientos históricos. América Latina dejaba de alinearse con el mundo anglosajón y giraba unos grados para aprender del ejemplo italiano y de las nuevas ideas nacionalistas y fascistas que surgían en otros países europeos. Ese nuevo horizonte político calzaba muy bien con la fiebre vanguardista inoculada por el virus revolucionario. Los artistas querían renovación, cambio, novedad. La modernidad estaba transformando las ciudades y al ser humano con los adelantos tecnológicos, y las ideas y las estéticas tenían que ir de la mano. Con la modernolatría vino también la búsqueda de las identidades nacionales y la reivindicación de los personajes vernáculos. El Boletín Titikaka, publicado en Puno, o la poesía de Carlos Oquendo de Amat, establecieron un vínculo entre el indio de los Andes y la modernidad de las fábricas y de los anuncios luminosos. Ya antes el peruano José Sabogal —y sus discípulos Julia Codesido y Enrique Camino Brent- habían inventado el indigenismo plástico. Borges, Ricardo Güiraldes, Oliverio Girondo, Pedro Figari y los demás escritores y artistas que orbitaron en torno a la revista Martín Fierro, en Argentina, se habían obsesionado con el gaucho, el lenguaje argentino, la pampa, y habían inventado el criollismo de vanguardia. En el Caribe hubo una búsqueda de las raíces negras. Alejo Carpentier, Nicolás Guillén, Luís Pales Matos y varios otros mantuvieron la sonoridad y el ritmo del habla coloquial negra en sus escritos. Los verde-amarillos exaltaron al tupí primitivo y expresaron sus críticas a la burguesía en sus poemas. En México, patrocinados por José Vasconcelos, los muralistas habían salido en busca del indio y del campesino para aprender de sus artesanías y de su folklor. El color local brotó por todas partes. La necesidad de encontrar una identidad nacional, un hecho diferencial que concentrara las particularidades esenciales de cada país, estimuló la cultura de forma excepcional. La modernidad llegaba en forma de regreso a lo autóctono; más concretamente, en forma de recuperación y actualización estilística de lo autóctono. Para el arte era un estímulo fabuloso; para la política, en cambio, estas ideas nacionalistas, esencialistas y revolucionarias encaminaron a la derecha y a la izquierda del continente por un nuevo sendero nada luminoso.

A partir de 1930 empezaron las grandes revoluciones de una derecha nacionalista y militar que se propuso hacer, en el ámbito público, una transformación similar a la que desarrollaba la vanguardia nativista en los campos culturales. En Argentina, invocado, respaldado 
y alabado por el mayor poeta modernista, Leopoldo Lugones, el general Uriburu dio un golpe de Estado (en todos los países se les llamó revolución) que instalaría a los militares en la vida pública argentina por las siguientes cinco décadas. A Brasil llegó Getulio Vargas y en México empezaría el dominio absoluto del Partido Nacional Revolucionario, embrión del inmarcesible PRI. $Y$ en buena parte de los otros países surgirían nuevas dictaduras: la de Rafael Trujillo en República Dominica, la de Jorge Ubico en Guatemala, la de Gerardo Machado en Cuba, la de Maximiliano Hernández Martínez en El Salvador, la de Luis Miguel Sánchez Cerro en Perú, la de Tiburcio Carías en Honduras... Unas eran de derecha y las otras podían autodenominarse populares 0 de izquierda, pero todas tenían un mismo elemento en común: eran nacionalistas.

Lo curioso del caso colombiano es que recorrió un camino distinto, casi inverso. Desde finales del siglo XIX hasta 1930, mientras el resto de América Latina estuvo gobernada por partidos liberales, republicanos o, como los radicales argentinos, mezcla de liberalismo, socialdemocracia, desarrollismo y nacionalismo, en Colombia hubo una hegemonía conservadora que impuso un ritmo, digamos, tímido hacia la modernidad. A pesar de que el Partido Conservador era nacionalista, su rechazo a las innovaciones estéticas y a las reivindicaciones populares no lo inclinaba a promocionar experimentos como el muralismo mexicano o el indigenismo peruano. En Colombia tuvimos que esperar hasta 1929 para que un grupo de artistas y escritores buscara el amparo de la diosa Bachué y lanzara consignas similares a las que habían resonado en otros países desde principios de los años veinte. Su nombre, los bachués, era un homenaje a una obra de Rómulo Rozo, un joven boyacense que en 1924, a los veinticinco años, viajó a Francia y allí realizó las primeras esculturas colombianas inspiradas en la iconografía indígena. Su obra maestra, Bachué, diosa generatriz de los chibchas, de 1925, era una escultura en bronce en la que el artista daba una forma animal a la diosa muisca. Lo irónico es que a Rozo, como a tantos otros latinoamericanos, se le despertó la pasión americanista en París, no en Boyacá, y por eso, a la hora de buscar referentes estéticos indígenas, acabó mezclando las influencias prehispánicas e hindúes a las que había estado expuesto en el Louvre.

Sus herederos, los bachués, se presentaron al público en 1930 con un manifiesto firmado por Darío Samper, Darío Achury Valenzuela, Hena Rodríguez, Juan Pablo Varela, Tulio González y Rafael Azula. Influenciados por el indigenismo del peruano José Carlos Mariátegui, se propusieron "colombianizar a Colombia", afianzar el espíritu de la América india, avivar un ideal americanista. Querían que su diosa tutelar les mostrara el camino al "corazón de la tierra", un camino que abría la posibilidad a un nacionalismo de izquierdas, diferente al nacionalismo que Los Leopardos, y más parecido al que predominaba en México.

De manera que la vanguardia plástica de corte indigenista empezaba en Colombia en ese año, en el 30, de la mano de un gobierno liberal y de intelectuales afines que, como Germán Arciniegas, darían a conocerla en los diarios nacionales. Algunos de estos artistas, como Luis Alberto Acuña, no tardarían en dar el predecible salto del lienzo a las paredes. Toda América Latina seguía absorta con el ejemplo mexicano, y en Colombia, gracias a Alfonso López Pumarejo, y en especial a Jorge Zalamea, un entusiasta del muralismo que de pronto se vio a sí mismo en el cargo que tuvo Vasconcelos cuando puso a Rivera, a Orozco y a Siqueiros a pintar los edificios públicos del D. F., Ministro de Educación, y que no dudó en apoyar el incipiente muralismo colombiano. En 1930 había vuelto al país, para dirigir la Escuela de Bellas Artes de Medellín, Pedro Nel Gómez, y en 1935 ya tenía el ambicioso encargo de pintar, ni más ni menos, el Palacio Municipal. Muralismo criollo a toda marcha, muralismo paisa que colombianizó los elementos que hicieron célebres a sus referentes mexicanos: la reivindicación social, el trabajo colectivo, la epopeya histórica, la exaltación de los oprimidos, las alusiones políticas: toda una estética y una deriva ideológica que ya había contagiado al continente entero con resultado notables en países como Brasil, gracias a Cândido Portinari, y variaciones interesantes en Argentina, con Antonio Berni y sus murales portátiles.

Esta irrupción de arte nuevo de corte nacionalista y popular, que sintonizaba a Colombia con el resto de América Latina, despertó una enorme resistencia por parte del Partido Conservador. La voz flamígera que lo condenó fue la de su líder, Laureano Gómez, el tradicionalista, el ultracatólico, el tomista que no dudó, más bien lo hizo como consecuencia de su misión moral, en condenar toda expresión literaria o plástica que se alejara de su visión católica de la vida y del mundo. Lo moderno le produjo urticaria, bien se tratara del fascismo de Mussolini o de la poesía de León de Greiff, y desde el El Siglo, su tribuna, su Twitter, emprendió una lucha estético-ideológica con la generación de los Nuevos y de ahí en adelante. No dejó títere con cabeza. Cuaderno del trópico, un poemario del bachué Darío Samper, le pareció un "folleto detestable, mal 
oliente, asqueroso" (Gómez, 1984, p. 67). La Revista de las Indias, la publicación insignia del Ministerio de Educación bajo el gobierno de López Pumarejo, la encontró execrable, un púlpito progre que se atrevía a publicar "cartas mariconas y una especie de romance del marica del citado García Lorca" (p.72). Laureano Gómez también renegó del Libro de los poetas, una antología que se había nutrido del "repugnante ámbito moral" (p. 71). que tanto gustaba a la izquierda colombiana, y se ensañó, con más saña si cabe, con León de Greiff, el poeta que según Laureano había convertido la poesía en el pasatiempo vulgar de la gleba incivilizada.

Cuando se enteró de que le habían dado las paredes de edificios públicos a Pedro Nel Gómez para que repitiera la gesta del "expresionista" Diego Rivera, encontró una prueba más de la corrupción moral del gobierno de López Pumarejo. Todos los ismos importados de Europa le parecían catastróficos, un "plástica mendaz" inspirada en civilizaciones paganas, Asiria, Egipto, el México prehispánico, no en la única que estaba en posesión de las verdades morales y espirituales legadas por Dios a la humanidad a través de la Iglesia Católica, la occidental hispánica. De la estética a la moral y finalmente a la política: todo era parte de lo mismo, y por eso Laureano estuvo dispuesto a llevar hasta el Congreso de la República un debate, cuando Jorge Eliecer Gaitán, Ministro de Educación en ese entonces, expuso en 1940 los desnudos de Débora Arango.

Mientras peleaba con la izquierda cultural patrocinada por el liberalismo, en su propio partido se enfrentaba a los Leopardos. La aparición pública de Gilberto Alzate Avendaño, emulador de Mussolini, camorrero y vehemente, puso en peligro la unidad del partido. Laureano tuvo que empeñarse a fondo para asegurar su liderato. Las cosas se le complicaban, los jóvenes nacionalistas querían menos cháchara parlamentaria y más acción callejera, actos heroicos encaminados a la imposición viril de un proyecto político autocrático y totalitario, y qué le vamos a hacer, Laureano era un fanático virulento, autoritario y convencido de tener la razón en todo, la razón moral, además, pero no era un fascista, al menos no antes de 1953, cuando quiso endilgarle a Colombia una Constitución corporativista, similar a la que impuso Getulio Vargas en Brasil en 1937. Se lo recordó a los niños malos de su partido: "el genuino conservador hace de la patria el segundo de los sentimientos afectivos. Deséala civilizada, y por eso es enemigo de la barbarie; la quiere libre, y es enemigo de la opresión; acata el orden constitucional, porque abomina de la dictadura" (Henderson, 1985, p. 56). Era un jalón de orejas en toda regla. El líder conservador quería gobernar, sin duda, pero no sobre una recua de "temblorosos idiotas".

Laureano venció en su pulso interno, y eso forzó a los Leopardos -Alzate Avendaño incluido- a salir del conservatismo y formar su propio partido de ultraderecha, Acción Nacionalista Popular. Y si por ahí llovía, por aquí no escampaba. Unos años antes, en las filas del liberalismo se había dado una escisión similar. En 1933 Jorge Eliécer Gaitán trató de crear un partido nuevo, de izquierdas, inspirado en posturas más radicales que las del liberalismo. Lo llamó UNIR, Unión Nacional Izquierdista Revolucionaria, y fue un reflejo del nuevo espíritu que alumbraba entre los jóvenes. Tanto los Nuevos de izquierda como los Nuevos de derecha trataban de renovar sus partidos con ideas más radicales, aunque con mucho menos éxito del esperado. Hubieran podido unirse en algún momento, como ocurrió con los nacionalistas de izquierda y de derecha en otros países. Al fin y al cabo, tanto Gaitán como Álzate Avendaño emulaban en su apariencia o en sus gestos a Mussolini, y su influjo en el primero quedaba reflejado en su propuesta de corporativizar las tierras improductivas, promover "un fuerte impulso nacionalista" y promover "el nacimiento de una mística profunda en servicio de un nuevo equipo de ideas" (Gaitán, 1968, p. 255), y en el segundo en su propósito de crear "un mito nacional, un ideal superior que cohesionara todos los esfuerzos vitales de la República" (Citado en Ayala, 2007, p.77).

Esta mezcla de nacionalismo de izquierda y de derecha no fue rara en América Latina. En Brasil, Getulio Vargas incorporó a su Gobierno a la vanguardia de izquierda y a la vanguardia fascista, y él mismo alternó entre el fascismo, la democracia, el nacionalismo de izquierda y el populismo. Argentina, después de Perón, también fue una mezcla incomprensible de fascismo y nacionalismo de izquierda, y ni hablar de Paraguay, Bolivia o Panamá, donde el Movimiento Febrerista, el Movimiento Nacionalista Revolucionario y la Doctrina Panameñista fueron un revoltijo de fascismo e izquierdismo popular. En Colombia nada de esto ocurrió. Ninguna de las facciones nacionalistas, ni la fascista de los Leopardos ni la popular de Gaitán, logró imponerse; tampoco se amalgamaron, y el resultado fue negativo para el arte, pues sin gobiernos nacionalistas el muralismo y el indigenismo no prosperan, y positivo para la política, porque fortaleció las instituciones y los anticuerpos que recelan de la dictadura benevolente del caudillo populista, y de la dictadura autoritaria del general salvapatrias. 
En otros países, los gobiernos nacionalistas con tentaciones autoritarias se apropiaron del muralismo o del indigenismo para rubricar su compromiso popular y su carácter revolucionario. Convertidos en escuelas oficiales, mostraban públicamente el compromiso de los gobernantes con los personajes autóctonos de la nación, con los indígenas y los campesinos, y con las reivindicaciones que pedían justicia, autodeterminación política, progreso, antiimperialismo y demás consignas del izquierdismo popular. En México, el caso más visible, el muralismo formó parte de una política de Estado. En las paredes de México se reescribió la historia de la Revolución y se remarcó el sello progresista del nuevo partido en el poder. Era una instrumentalización de la cultura que se repitió en el Brasil de Getulio Vargas, en el Perú de Manuel Odría, en la Bolivia de Paz Estenssoro o en El Salvador de Maximiliano Hernández Martínez.

García Márquez mencionaba a este último dictador, Hernández Martínez, en su discurso del Nobel. Mencionaba a ese "déspota teósofo" que había ordenado cubrir los postes de la luz con papel rojo para combatir una epidemia de escarlatina, ejemplo de realismo mágico, pero no mencionaba que aquel loco delirante decía obtener esas recetas surreales de un grupo de médicos invisibles que consultaba en sesiones de espiritismo. Ese loco que se creía intelectual y patrono de las artes, más que ejemplo de realismo mágico, era en realidad ejemplo de la barbarie y del cinismo latinoamericano. En 1932 había ordenado la matanza de unos 30.000 campesinos e indígenas que se habían sublevado, un etnocidio en toda regla, para después promover el arte y la literatura indigenista de su país. Salarrué en las letras, José Mejía Vides en la plástica, dos de los más importantes creadores de su país, ambos fueron sus amigos y en ambos, como en muchos otros, se escudó para limpiar su nombre. Qué mejor lugar para enterrar el asesinato masivo de indígenas que bajo la plaqueta progresista de un proyecto cultural bienpensante.

\section{IV}

Hubo muchos artistas que se dieron cuenta de esta complicidad nociva entre las dictaduras populares y nacionalistas y el arte que, habiendo sido vanguardia en los veinte, en los treinta y cuarenta se convertía en una escuela oficial. El caso más notorio es Borges, el crioIlista que ya no pudo soportar las apelaciones nacionalistas y el machismo vernáculo de los dictadores de los treinta y cuarenta, y que por eso mismo renegó de su pasado vanguardista y de todos los esfuerzos que hizo por reivindicar el "idioma de los argentinos" y la nostalgia por la pampa, el arrabal, el compadrito o el gaucho. Más aún, su literatura se desenraizó para tomar vuelos metafísicos. Se hizo universal, cosmopolita, fantástica, y con estos ejercicios purgados de nativismo demostró que para ser un escritor argentino no había que abordar ningún tema nacional ni hacer ninguna reivindicación patriotera. Era una propuesta estética, sí, pero sobre todo un reflejo de sus ideas políticas y de la abominación que expresaba por las dictaduras de Uriburo y de Pedro Pablo Ramírez, y más aún por el populismo cacofónico, sentimental y kitsch que se inventó Perón en 1945.

Borges no fue el único que rechazó la cultura que le hacía el cuarto a los autócratas nacionalistas. Los comunistas también lo hicieron, de una forma igualmente radical, aunque más concreta que metafísica, eso sí. Y es que nadie como ellos sufrió el acoso de estas dictaduras y de estos gobiernos populistas que se enunciaban como izquierdistas mientras promovían el antisemitismo y el odio a todo lo extranjero. Los enemigos de estos gobiernos fueron los comunistas, los liberales y los judíos, y siempre por lo mismo, eran internacionalistas, el pecado que el nacionalismo predominante en la política latinoamericana entre 1930 y 1960 no podía tolerar. Y el arte que estaban promoviendo los comunistas no remetía, ni por asomo, a la patria o a los personajes vernáculos, fácilmente reconocibles como símbolo de lo propio. Estaban experimentando con las formas, con una estética racional y en absoluto acorde con el sentimentalismo patriotero o populista, que desembocó en la abstracción geométrica, el arte concreto que todos los nacionalistas abominaron. Surgió en los cuarenta en Argentina - para horror de Perón-, luego llegó a Brasil, impregnó su poesía y a sus mejores arquitectos — Lucio Costa fue socialista y Oscar Niemayer murió con su carnet de comunista-, y siguió después por toda América Latina. Los argentinos que lo promovieron fueron comunistas, algunos judíos, otros hijos de emigrantes, todos interesados en promover el internacionalismo, la conversión del artista en obrero, la utilidad y el destino industrial del arte, y la creación de mundos nuevos. Como el creacionismo de Huidobro, los artistas concretos se propusieron replicar los procesos de creación de la naturaleza, no su semblante externo, mucho menos sus particularismos nacionales.

Los liberales no desarrollaron una estética ni una expresión artística, pero una vanguardia que llegó a Latinoamérica en los treinta, y que se enfrentó por igual 
al nacionalismo y al comunismo, acabaría llevando a muchos de sus exponentes a las filas del liberalismo, del anarquismo o de la izquierda heterodoxa. Esa vanguardia, claro, fue el surrealismo, el instigador de la fiebre imaginativa que brotaba de las vísceras, de las gónadas o del inconsciente de cada cual, no de una patria, de una clase o de la servidumbre a una causa moral, por primorosa que esta fuera. En Perú, sus más furiosos partidarios se enfrentaron al indigenismo que había legado Mariátegui, y que tanto en la pintura, con José Sabogal, y en la literatura, con José María Arguedas, se había convertido en un horizonte insoslayable. César Moro y Emilio Adolfo Westphalen fueron esas dos voces críticas. Moro, especialmente; Moro el maricón de quien se burlaban los estudiantes el Colegio Militar Leoncio Prado, donde dio clases profesor; Moro el profesor de francés que deslumbró a un cadete Vargas Llosa de quince años, que por entonces solo escribía novelitas porno pero que luego publicaría un par de ensayos sobre el pasado surrealista de su profesor. Ese César Moro fue el artista latinoamericano menos dispuesto a soportar el chantaje moral del indigenismo, que estaba forzando a los artistas a demostrar sensibilidad social y compromiso político. La pintura y la literatura, recordaba Moro, no eran un asunto de ángeles sino de humanos, mejor aún, de canallas. ¿Para qué el arte si no se podía hacer lo que a uno le diera la gana? ¿Para qué el arte si la imaginación debía someterse a las directrices bienpensantes de los salvadores de los oprimidos? ¿Para qué el arte si no cabían en él los deseos, las perversiones, las pesadillas y los instintos más antisociales y aterradores? Por nacionalistas, moralizantes o hipócritas, el muralismo y el indigenismo empezaban a despertar un fuerte rechazo entre algunos creadores.

En México fueron Rufino Tamayo, Octavio Paz y José Luis Cuevas quienes dieron una pelea similar. Entre los tres criticaron el falso progresismo de los muralistas, las mentiras históricas que retrataba, el juego perverso que tenían con el poder, y el autoritarismo institucional que habían impuesto para impedir nuevas experimentaciones artísticas. México, el país que primero y con más brío recibió el impulso de las vanguardias, se había petrificado en el tiempo. Excepto por los Contemporáneos en poesía, y alguna que otra figura anárquica en la pintura, como Frida Kahlo o Nahui Olin, no había habido una renovación en la cultura. En los cincuenta se seguían pintando los mismos indios y los mismos campesinos, y el estilo no había variado. Seguían los volúmenes enormes, los colores terrosos, las escenas tremebundas; hasta los gringos, oh vergüenza, ya habían aprendido a pintarrajear los mismos motivos y ahora los vendían baratísimo, hasta los regalaban. Era insoportable, soporífero, no se podía respirar, y por eso los jóvenes, no sin mucha resistencia, se sobrepusieron finalmente al programa muralista. Todo tardó: solo hasta mediados de los cincuenta la plástica latinoamericana volvía a renovarse, esta vez impulsada por el surrealismo y la abstracción, y la literatura empezaba a alejarse de los temas de la tierra para darle más importancia a la forma que al contenido de las novelas. Esta vez, y ya era hora, Colombia estuvo lista para no perder el tren de la contemporaneidad.

\section{V}

En 1946 los conservadores volvieron al poder con espíritu de reconquista moral y revancha política. Laureano tenía cuentas pendientes con la cultura colombiana, y los murales pagaron el pato. Algunos fueron borrados, otros ocultados tras cortinas, y ninguna otra pared pública fue dispuesta para la intervención artística. Por eso, aunque no solo por eso, ni el muralismo ni el indigenismo llegaron a convertirse en escuelas oficiales, y quizás eso explica que no hubieran surgido movimientos de oposición individualistas y anárquicos. El surrealismo, por ejemplo, no arraigó en Colombia, y en sus filas el único que militó fue Vidal Echavarría, un poeta y pintor costeño que quiso llevar la insurrección del sinsentido y de la pulsión a la cultura colombiana. Su influjo, sin embargo, fue débil y hoy pocos lo recuerdan. Quizás porque en Colombia, a diferencia de otros países, el liberalismo que defendía la libre autonomía del individuo sobrevivió a la crisis del 29, no hubo necesidad de un movimiento plástico que liberara el deseo y la fantasía individual. Es solo una hipótesis, débil sin duda, pero ahí la dejo. El caso es que la fugaz aparición de Echevarría no se puede comparar con las luchas que dio el surrealismo en países como Chile, donde los poetas de La Mandrágora se enfrentaron al establishment que representaba Pablo Neruda, otro poeta que también, en sus años mozos, sintió el influjo surrealista; o en las capitales de México, con Paz, de Perú, con los ya mencionados Moro y Westphalen, o de Argentina, con Aldo Pellegrini, donde el surrealismo se perfiló como una fuerza revolucionaria centrada en el individuo y en la libertad de sus deseos, enemigos de toda coacción moralista, nacionalista o partidaria.

En Colombia, en los cuarenta y en los cincuenta, lo más parecido a esa insurrección individualista en contra de los dogmas estéticos y políticos dominantes fue la obra de Débora Arango. Ojo: no los candorosos desnudos 
que escandalizaron a Laureano Gómez, sino la pintura que consumó como reacción impetuosa y satírica al asesinato de Gaitán en 1948. A partir de entonces, la historia política del país se convirtió en un tema recurrente en su pintura. Arango pintó escenas referidas a la matanza de las bananeras de 1928, a las hordas enloquecidas durante el Bogotazo, a las mujeres victimizadas por la guerra partidista, a los manifestantes en las huelgas, a los símbolos patrios envilecidos. Pintó mujeres enloquecidas, mujeres en escenas descarnadas, mujeres deseadas y expuestas. Pintó a prominentes políticos, entre ellos al mismo Laureano y al dictador Rojas Pinilla, con una libertad y arrojo hasta entonces desconocidos en Colombia. Densas, lúgubres, mórbidas, esas pinturas traían hasta el presente la atmósfera viciada de una Colombia en guerra, trastornada por la intolerancia política y la sombría autoridad de las sotanas y de líderes que también eran lobos y batracios.

Esa misma irreverencia y desprecio por el dogma moral imperante, promovido por el catolicismo de cruzada que inspiró al Partido Conservador de Laureano Gómez, tuvo un impacto más inmediato y visible con la irrupción de los nadaístas, en 1958. Los jóvenes que siguieron en su algarada vital a Gonzalo Arango sí estaban claramente influenciados por el dadaísmo, el surrealismo y las primeras expresiones contraculturales estadounidenses, la beatífica, que no beata, generación beat. El suyo fue un grito destructivo y anárquico, que de manera muy tardía sintonizó al país con las corrientes culturales que exaltaban la vida, lo maravilloso cotidiano, el amor, el sexo, el placer y los paraísos inducidos por las drogas. La violencia partidista que había empezado a comienzos de los años treinta, que se había incrementado con el regreso de los conservadores al poder en 1946, y que había degenerado en una silenciada guerra civil a partir de 1948, estaba detrás de la rebeldía nadaísta. Como los dadaístas, que en 1916 se reunieron en Zúrich dispuestos a destruir toda la cultura previa, responsable vicaria — según ellos - de la Primera Guerra Mundial o, como mínimo, barrera inocua que no frenó la monstruosidad del nacionalismo y de los caudillos belicosos, el nadaísmo también despreció la cultura nacional y el clima moral de una Colombia que acababa de salir de una guerra, una guerra que había producido pilas y pilas de cadáveres en los campos y un aburrimiento casi tan mortífero en sus rezanderas y precarias ciudades.

La opción política de este grupo de jóvenes fue la rebelión hedonista. Como decía Gonzalo Arango, los nadaístas militaban en las filas del P.C. Pero no se equivoque, amigo, no en el Partido Comunista, sino en los Pecados
Capitales, todos y cada uno de ellos e incluso más, porque a los siete del catolicismo añadían “El Vómito, La Concupiscencia del Estiércol, La infamia de la Belleza y La Exaltación de la Iniquidad Humana" (Arango, 2018, p. 56). No querían, como Huidobro, hacer florecer a la rosa en el poema, sino preñarla. La dignidad del cuerpo les importaba más que la dignidad del alma; la suya era una cruzada encaminada a "colmar los apetitos del deseo", "realizar los impulsos vitales de nuestro ser" ( $p$. 65), y también, cómo no, rebelarse contra cualquier tipo de opresión y dogmatismo que no fuera el que ellos mismo predicaban.

La poesía fue para los nadaístas sinónimo de libertad y vida, y por eso fueron poetas y vivieron como poetas y fueron sacrílegos y apasionados. Combinaron las horas de escritura con perfomances que publicitaron de manera espectacular su mensaje. Quemando libros, robando hostias o saboteando actos académicos, promovieron una actitud beligerante y transgresora, típica de la vanguardia revolucionaria europea, que por fin inyectó a la cultura colombiana un antídoto para la solemnidad, ese gran vicio conjurado temporalmente por el Tuerto López, Vidales y de Greiff, pero reinstaurado por los piedracelistas en los años cuarenta: ay, Eduardo Carranza y sus himnos patrioteros. El impulso de esta rebelión juvenil llegaría a Cali, donde se mezcló con la literatura, el cine, la música, la fotografía, el teatro y la pintura en los sesenta y setenta, generando una gran fiesta creativa de donde saldrían figuras como Andrés Caicedo, Carlos Mayolo y Luis Ospina, un escritor y dos cineastas que ampliaron los registros estéticos colombianos con la truculencia gótica y las historias de jóvenes en busca de existencias apasionadas y creativas.

\section{VI}

Pero dejemos a los hippies y volvamos a Laureano, cómo no, aunque esta vez para exonerarlo. Y es que a pesar del odio que les profesó y de los mucho que los criticó, el acta de defunción de los bachués y del muralismo colombiano no el político pasadista sino la modernizante y progresista Marta Traba. Enemiga del nacionalismo, un concepto que la crítica colombo argentina encontraba, a la vez, vago y siniestro, no le concedió mucho valor a la obra Pedro Nel Gómez, que le preció conservadora; ni a la de Luis Alberto Acuña, renacentista y puntillista; ni a la de Alipio Jaramillo, fruto de la "ortodoxa tradición tridimensional". De manera categórica, en un ensayo de 1960 decía que 
en Colombia "la pintura es un arte sin pasado" (Traba, 1960), sentencia con la que daba a entender que antes de la generación que ella misma apadrinó, la de Alejandro Obregón, Fernando Botero, Edgar Negret, Eduardo Ramírez Villamizar, Enrique Grau, etc., no había nada digno de mención. Ni Débora Arango ni indigenistas ni muralistas, nada. El arte colombiano empezaba en los cincuenta, con la vocación modernizadora del expresionismo figurativo de Obregón y de la abstracción de Ramírez Villamizar y Negret, artistas que actualizaban la fauna local y las geometrías prehispánicas con estilos cosmopolitas. Con ellos el arte tomaba vuelo, algo novedoso. La raíz nacional dejaba de ser un cepo que forzaba a sus obras a estar a ras de suelo, denunciando injusticias, exaltando al indio o al campesino, o promocionando esta o aquella ideología. Más bien, les permitía hablar de experiencias estéticas universales, detonadas por la forma y el color y por cierta reminiscencia americanista, en absoluto reñida con los préstamos culturales del resto del mundo. Al igual que con Tamayo en México, con el modernismo tropical brasileño o con la pintura abstracta del peruano Fernando de Szyszlo, estos pintores y escultores metían a Colombia en la nueva etapa que se abría para el arte latinoamericano.

Mientras esto ocurría en la plástica, García Márquez hacía algo muy similar en la literatura. Las herramientas narrativas desarrolladas por los escritores modernistas anglosajones y europeos, en especial Joyce, Faulkner, Woolf y Kafka, encontraban en el trópico colombiano a un narrador que vio en ellas la clave para abordar la reciente historia de Colombia de una forma totalmente novedosa. La literatura colombiana se desembarazaba, también y por fin, de la temática nativa, de la tierra y de sus siervos, para preocuparse por la técnica. García Márquez se dio cuenta de una cosa: lo importante no era qué se iba a contar sino cómo. Los puntos de vista del narrador, los monólogos interiores, los saltos temporales: ahí estaba el misterio de la literatura. Para hablar de la violencia partidista de los años cincuenta, por ejemplo, había que dejar de denunciar las muertes porque lo interesante era otra cosa: el vivo que sudaba escondido detrás un matorral mientras oía mochar cabezas. Las agujas de la literatura colombiana también se alineaban con las del mundo moderno, y bueno, sabemos cómo termina la historia. Nunca la cultura colombiana fue tan cosmopolita como con las historias pueblerinas de García Márquez.

\section{VII}

Bien ubicada en el nuevo mundo global y cosmopolita de las Bienales y de las ferias contemporáneas, algunas expresiones culturales colombianas han retomado prácticas latinoamericanas en una suerte de comeback, de retour, de giro de tuerca minimalista del muralismo, que está siendo determinante en el rumbo de las nuevas prácticas del arte contemporáneo. La protagonista indiscutible de este fenómeno es Doris Salcedo, la artista que con sus grandes instalaciones está poniendo en primer plano, una vez más, igual a como hicieron indigenistas y muralistas, a las víctimas de este mundo.

Dije "instalaciones", pero en realidad, si se miran con detenimiento, es fácil ver que las obras de Salcedo están emparentadas con el proyecto muralista latinoamericano. No usa paredes, pero sí suelos; no reivindica concretamente a los oprimidos y explotados, pero sí a una categoría amplia, las víctimas, en la que entran los inmigrantes y las minorías raciales; sus obras no tienen connotaciones ideológicas, partidistas o nacionalistas, pero sí reinstalan con enorme fuerza el compromiso moral del arte y del artista; no pretende reescribir la historia de los países, pero sí evitar el olvido de quienes han muerto en las tragedias que escupe la historia. Este nuevo compromiso social y moral del arte ya no tiene, como el muralismo mexicano, una ideología revolucionaria ni un compromiso con la construcción de la nacionalidad; se inscribe, más bien, en la nueva ola de corrección política que está determinando las prácticas artísticas y el funcionamiento de las instituciones culturales en el mundo entero. No se trata solo de las víctimas, aunque desde luego que ellas tienen un lugar fundamental en esta nueva sensibilidad, se trata también del feminismo, de la reivindicación de las identidades minoritarias - la queer, sobre todo-, de la denuncia de la violencia policial y los abusos de algunos Estados (solo occidentales, de lo contrario sería políticamente incorrecto), y sobre todo, y cada vez con más fuerza y urgencia, del cambio climático. Basta pasar revista a las obras y películas premiadas en los últimos certámenes internacionales para ver por dónde van los tiros. El arte y la cultura en general, tanto en Colombia como en el mundo entero, han resucitado la dinámica del compromiso, del deber moral y de la corrección, y no es difícil vaticinar que, en unos años, cuando la escena política se calme y la incorrección deje de ser una forma exitosa de autopromoción para presidentes (Bolsonaro, Trump, Salvini), volverá la agitación individualista al arte. Mientras tanto, los museos seguirán exponiendo las tragedias ambientales y el sufrimiento 
de las víctimas, y por una temporada podremos ver cómo el mundo entero se latinoamericaniza y hace suyas las reivindicaciones que inspiraron el arte que se hizo por estas tierras, siempre confusas y por lo general ignoradas, en la primera mitad del pasado siglo. Madrid, 8/09/19

\section{Referencias}

Arango, Gonzalo (2018). Obra negra. Madrid: Punto de Vista Editores.

Arias Trujillo, Ricardo (2007). Los Leopardos. Una historia intelectual de los años 1920. Bogotá: Ediciones Uniandes.

Ayala Diago, César Augusto (2007). El porvenir del pasado: Gilberto Alzate Avendaño, sensibilidad leoparda y democracia. La derecha colombiana de los años treinta. Bogotá: Universidad Nacional de Colombia.
Gaitán, Jorge Eliecer (1968). Antología de su pensamiento social y económico. Bogotá: Ediciones Suramericana.

Gómez, Laureano (1984). Obras completas. Tomo I. Crítica sobre literatura, arte y teatro. Bogotá: Instituto Caro y Cuervo, Bogotá.

Henderson, James D. (1985). Las ideas de Laureano Gómez. Bogotá: Tercer Mundo.

Loaiza Cano, Gilberto (2008). “Los Arquilókidas” [1922] en: Las vanguardias literarias en Bolivia, Colombia, Ecuador, Perú y Venezuela. Madrid: Editorial Vervuert.

Parra del Riego, Juan (1943). Poesía. Montevideo: Biblioteca de Cultura Uruguaya.

Traba, Marta (1960). La Pintura de hoy en Colombia. Revista Plástica (Bogotá, Colombia), no. 17 